\title{
Experimental investigation into the effect of surface roughness and mechanical properties of 3D-printed titanium Ti-64 ELI after heat treatment
}

\author{
L. Lebea ${ }^{1,2^{*}}$ (D, H. M. Ngwangwa ${ }^{2}$, D. Desai ${ }^{1}$ and F. Nemavhola ${ }^{2}$
}

\begin{abstract}
The initial stability after implantology is paramount to the survival of the dental implant, and the surface roughness of the implant plays a vital role in this regard. The characterisation of surface topography is a complicated branch of metrology, with a huge range of parameters available. Each parameter contributes significantly towards the survival and mechanical properties of three-dimensional printed specimens. The purpose of this paper is to experimentally investigate the effect of surface roughness of three-dimensional printed dental implants and three-dimensional printed dogbone tensile samples under areal height parameters, amplitude parameters (average of ordinates), skewness parameters and mechanical properties. During the experiment, roughness values were analysed, and the results showed that the skewness parameter demonstrated a minimum value of $0.59 \%$. The three-dimensional printed dental implant recorded the arithmetic mean deviation of the assessed profile with a 3.4-mm diameter at $43.23 \%$ and the three-dimensional printed dental implant with a $4.3-\mathrm{mm}$ diameter at $26.18 \%$. Samples with a complex geometry exhibited a higher roughness surface, which was the greatest difficulty of additive manufacturing when evaluating surface finish. The results show that when the ultimate tensile stress decreases from 968.35 to $955.25 \mathrm{MPa}$, the arithmetic mean deviation increases by 1.4\%, and when ultimate tensile stress increases to $961.18 \mathrm{MPa}$, the arithmetic mean deviation increases by $0.6 \%$. When the cycle decreases from 262,142 to 137,433 , the arithmetic mean deviation shows that less than a $90.74 \%$ increase in the cycle is obtained. For the three-dimensional printed dental implants, the higher the surface roughness, the lower the mechanical properties, ultimately leading to decreased implant life and poor performance.
\end{abstract}

Keywords: 3D printing, Surface roughness, Powder bed fusion

\section{Introduction}

The mechanical behaviour of a structure is one of the most important factors to consider in the design of a dental implant (Vaidya and Pathak 2019). The use of additive manufacturing is a useful tool in the design and production of dental implants (Oliveira and Reis 2019); however, despite many attempts, this technology is still

\footnotetext{
*Correspondence: lebealc@unisa.ac.za

'Department of Mechanical and Mechatronic Engineering, Tshwane University of Technology, Pretoria, South Africa

${ }^{2}$ Unisa Biomechanics Research Group, Department of Mechanical and Industrial Engineering, University of South Africa, Pretoria, South Africa
}

in the initial research stage (Ahsan 2016; Chang Tu et al. 2020). The effect of surface roughness on the final product produced by additive manufacturing still lacks attention, especially when printing complex structures.

The production of this material leads to the possibility of using three-dimensional (3D) printing in the field of tissue engineering, which allows for the production of scaffolds with patient-specific dimensions (Becker et al. 2015a; Ren et al. 2021). Regardless of the increased effectiveness of titanium, the capability to produce parts or products with high productivity and superior quality

\section{Springer Open}

(๑) The Author(s). 2021 Open Access This article is licensed under a Creative Commons Attribution 4.0 International License, which permits use, sharing, adaptation, distribution and reproduction in any medium or format, as long as you give appropriate credit to the original author(s) and the source, provide a link to the Creative Commons licence, and indicate if changes were made. The images or other third party material in this article are included in the article's Creative Commons licence, unless indicated otherwise in a credit line to the material. If material is not included in the article's Creative Commons licence and your intended use is not permitted by statutory regulation or exceeds the permitted use, you will need to obtain permission directly from the copyright holder. To view a copy of this licence, visit http://creativecommons.org/licenses/by/4.0/. 
is a challenge (Khan and Rahman 2017). Extra-low interstitial (ELI) titanium or Ti-64 ELI is a well-known light alloy characterised by excellent mechanical properties and corrosion resistance combined with low specific weight and biocompatibility (Kuss et al. 2015). This material is ideal for many high-performance applications (Moletsane et al. 2016).

The use of microscopes is becoming increasingly popular as technology in material characterisation (Bhardwaj and Shukla 2018). Surface roughness, which is an unavoidable phenomenon at machining, is usually strictly required when the processed materials are applied in structural components subjected to cyclic loads (Xiao et al. 2012). Surface roughness is usually characterised by an average geometric parameter, namely arithmetic mean roughness (Ra) (Öztürk and Kara 2020). Moreover, the accuracy and efficiency of roughness measurements are important to the modern industry (Ren et al. 2021). Surface treatments on titanium materials have been in existence for a long time (Marenzi et al. 2019; Jemat et al. 2015; Le Guéhennec et al. 2007); however, technologies involved in this treatment have evolved in the last 10 years (Kunrath 2020). It was reported that surface roughness plays a critical role in determining the life of the implant (Obiukwu et al. 2015).

The characterisation of surface topography and roughness is imperative in unfolding the wear and damage to surfaces (Suh et al. 2003). Surface roughness characterisation and the electron beam melting (EBM) process were analysed, and the authors found that the mean roughness value ( $\mathrm{Ra}$ ) agreed with that of the literature on the EBM process (Galati et al. 2019). Recently, five tensile specimens made of Ti-64 with different roughness profiles were examined experimentally, and the results showed the failure of Ti-64 to be highly sensitive to both magnitude and orientation of roughness (Sneddon et al. 2020). Surface roughness and texture can influence the biological response around implants; as such, it is paramount to investigate this phenomenon carefully (Barman and Das 2018). Experimental studies have been conducted to determine the surface roughness and morphology of 3Dprinted samples (Tang et al. 2021; Mooney and Kourousis 2020; Gora et al. 2016). However, despite many attempts, the performance-based parameters of 3D-printed Ti-64 ELI material are not well established. The aim of this study was to investigate experimentally the effect of 3Dprinted dental implants with 3.4 and $4.3 \mathrm{~mm}$ diameters and 3D-printed dogbone tensile specimen surface topography and mechanical properties under areal height parameters, amplitude parameters (average of ordinates) and skewness parameters. The outcome of this study can contribute significantly to understanding the variation between various roughness topographies of direct metal laser sintering (DMLS) 3D-printed samples.

\section{Materials and methods}

\section{Design and preparation}

The design of dental implants and dogbone tensile specimen was carried out by the authors at the University of South Africa using the Abaqus CAE software and then saved as a STL file format, which is one of the most common file formats used in the $3 \mathrm{D}$ printing process. The designed dental implants were of dimeters $3.4 \mathrm{~mm}$ and 4.3 $\mathrm{mm}$ and dogbone tensile specimens. TiziriTech (South Africa) was contracted to manufacture the dental implants through direct laser sintering 3D printing technique.

\section{D-printing of specimens}

Ten $(N=10)$ specimens of $3.4 \mathrm{~mm}$ and $4.3 \mathrm{~mm}$ diameter of dental implants and five $(N=5)$ dogbone tensile specimens were 3D printed (see Fig. 1). The direct metal laser sintering machine (EOS M290) is used for sample preparation on a titanium Ti-64 ELI powder (specifications listed

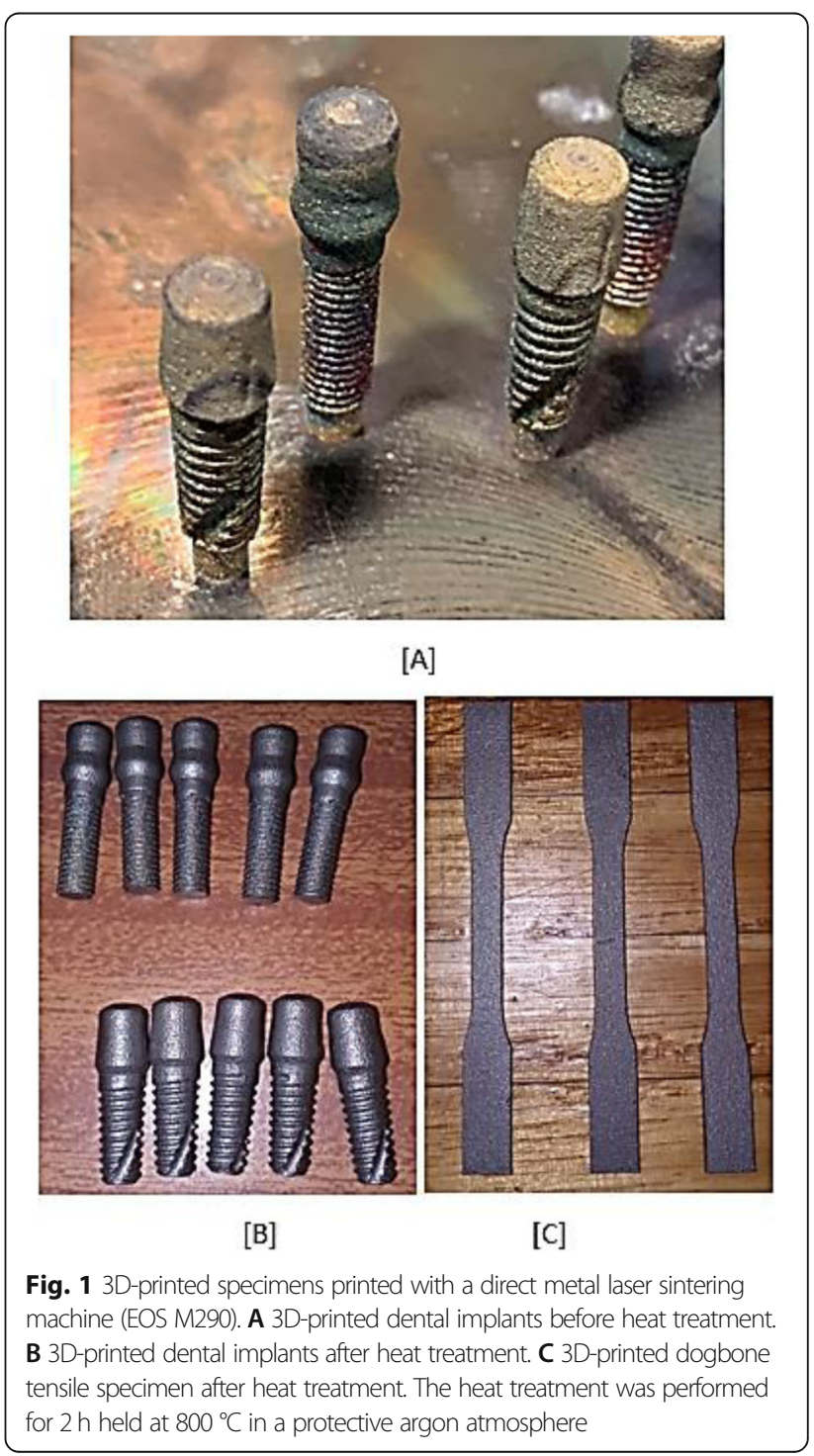


in Table 1). Before starting the sample building, the build plate is preheated to $40^{\circ} \mathrm{C}$. The average size of the particles was $39 \pm 3 \mu \mathrm{m}$. The layer thickness was fixed at $20 \mu \mathrm{m}$ with a volume rate of $1.68 \mathrm{~mm}^{3} / \mathrm{s}$. The total build speed depends on this volume rate, and many other factors such as exposure parameters of contours, supports, up and down skin, recoating time, Home-In, or LPM settings. The build job was processed by the EOS DMLS system: EOS M290, 63- $\mu \mathrm{m}$ mesh for powder sieving is recommended.

To increase the mechanical properties, the heat treatment procedure was performed for $2 \mathrm{~h}$ held at $800{ }^{\circ} \mathrm{C}$ in a protective argon atmosphere. Cooling was done at room temperature in a protective atmosphere to reduce oxidation. The chemical composition of the material is represented in Table 2.

\section{Surface roughness measurements after heat treatment}

To investigate the effect of performance-based parameters, the specimens were placed in a specimen holder of a confocal microscope ZEISS LSM 900 for materials (see Fig. 2). The surface roughness values of samples were measured at a horizontal direction of 3D-printed dental implants with 3.4 and $4.3 \mathrm{~mm}$ diameters and 3D-printed dogbone tensile test specimens. The master grain was adjusted until the optimum value was reached and 10x microscopic laser was selected. Surface roughness measurements were taken from $600 \times 600 \mu \mathrm{m}$ length on each specimen in a horizontal direction. Three specimens were selected in each group, namely a 3D-printed dental implant with V-type threads and a 3.4-mm diameter, a 3Dprinted dental implant with V-type threads and a $4.5-\mathrm{mm}$ diameter, and a 3D-printed dogbone tensile test specimen. The surface roughness values were determined by calculating the average of these measurements.

The surface topography algorithm is paramount in analysing roughness values. Three algorithms-areal height parameters (R), amplitude parameters (S) and skewness (Rsk) - are used to calculate these parameters (Godbey 2007). Average roughness is a value that calculates the absolute magnitude of surface features without considering the nature of the surface, and skewness is the ratio of the mean of the height values. However, the root mean square roughness

Table 1 Direct metal laser sintering machine (EOS M290) specifications

\begin{tabular}{ll}
\hline Parameter & Values \\
\hline Laser power & Yb fibre laser $400 \mathrm{~W}$ \\
Scan speed & Up to $7.0 \mathrm{~m} / \mathrm{s}$ \\
Wavelength & $1060-1100 \mathrm{~mm}$ \\
Build area & $250 \times 250 \times 325 \mathrm{~mm}$ \\
\hline
\end{tabular}

Table 2 Chemical composition of titanium Ti-64 ELI (extra-low interstitials) powder in wt.\%

\begin{tabular}{llllllllll}
\hline Al & $\mathbf{V}$ & $\mathbf{O}$ & $\mathbf{N}$ & $\mathbf{C}$ & $\mathbf{H}$ & $\mathbf{F e}$ & $\mathbf{Y}$ & Other elements & $\mathbf{T i}$ \\
\hline 6.50 & 4.50 & 0.13 & 0.05 & 0.08 & 0.012 & 0.25 & 0.005 & 0.1 & bal. \\
\hline
\end{tabular}

value accounts for the size disparity of features, as it presents an average roughness value.

\section{Tensile test experiment after heat treatment}

The dogbone tensile specimens were 3D-printed on an EOS 290 powder bed fusion printer. The specimens were prepared following ASTM standard E8/E8M-09 (standard test methods for the tension testing of metallic material) (Materials et al. 2006). The tensile test was performed on a 10-kN Instron electro-mechanical controlled testing machine (Instron, Norwood, MA, USA). The machine was loaded at a crosshead velocity of $5 \mathrm{~mm}$ per minute. For statistical considerations, five (5) 3D-printed specimens were tested. The specimens were finally fractured after necking. The maximum force, tensile stress at yield (offset $0.2 \%$ ), and ultimate tensile strength (UTS) were recorded and are presented in Table 6.

\section{Fatigue test after heat treatment}

The physical specimens were tested at a frequency of 10 $\mathrm{Hz}$ using an MTS Acumen fatigue machine until fracture occurred. A maximum load of $810.50 \mathrm{~N}$ was selected based on a previous study on titanium dental implants (Nagy and Griggs 2018). It was reported that under ISO protocol, testing in air and a normal saline solution is equivalent in terms of the likelihood of fracture versus runout (Nagy and Griggs 2018). The specimens were fixed according to the international standard of dynamic testing of single-post endosseous dental implants (BSI Standards Publication dentistry 2016). As such, the current study considered air as a testing

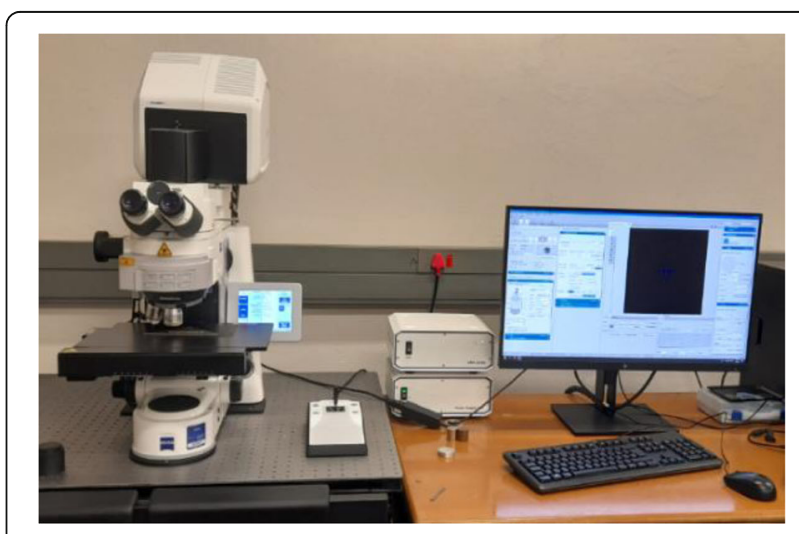

Fig. 2 Experimental set-up of surface roughness measurement using a confocal microscope ZEISS LSM 900 
environment. Dental implants with a diameter of 3.4 $\mathrm{mm}$ were $3 \mathrm{D}$-printed and tested experimentally.

\section{Results}

To evaluate the results, 18 visual signatures of all the surfaces were compared. The other information (2D roughness measurement profile) was used to aid in the analysis of the coefficient behaviour. The tests were carried out on the samples by selecting 3 equal points on the samples. The experimental results are then displayed in Figs. 4, 5 and 6, to calculate each parameter at the mean. The visual signatures of dogbone $3.4 \mathrm{~mm}$ and $4.3 \mathrm{~mm}$ dental implants are shown in Fig. 3. The graphs are plotted using the mean values of each roughness parameter. The comparison of the results obtained at different models indicates which model geometry is sensitive to the printing process according to the desired roughness level.

\section{Effect of heat treatment on surface roughness Arithmetic mean ( $R a$ and $\mathrm{Sa}$ )}

The underlying surface topography was characterised by measuring the arithmetic mean roughness values. The length of $600 \mu \mathrm{m}$ was used on the 3D-printed dogbone tensile specimen and 3D-printed dental implants with diameters of 3.4 and $4.3 \mathrm{~mm}$. A length of $600 \mu \mathrm{m}$ was used for the 3D-printed dogbone tensile specimens and 3D-printed dental implants with diameters of 3.4 and $4.3 \mathrm{~mm}$. Figure 4 compares the curves of the height parameter (Ra) and the amplitude parameter (Sa) of three instances of the magnitude of different nominal roughness of the surface.

Currently, most studies pay more attention to lower roughness values of $<5 \mu \mathrm{m}$, since it is suggested that $\mathrm{Ra}$ values of 3 to $5 \mu \mathrm{m}$ will be more favourable for

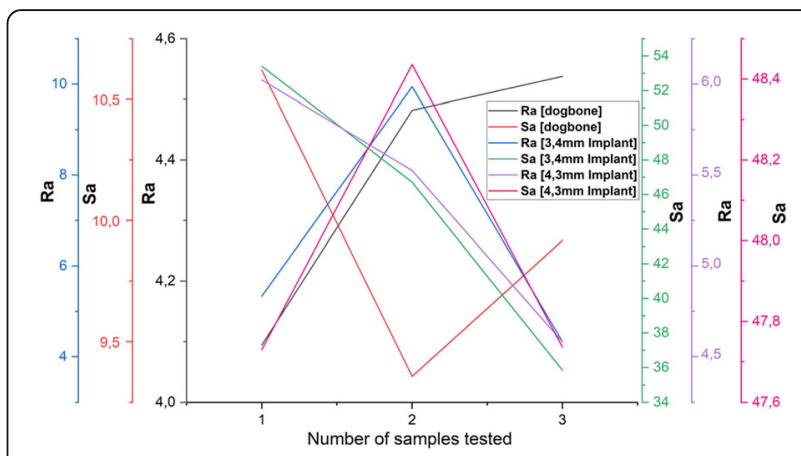

Fig. 4 Graphical representation of 3D-printed specimen results with a comparison of arithmetic mean roughness ( $\mathrm{Ra}$ and $\mathrm{Sa}$ ) $\mu \mathrm{m}$. A 3Dprinted dogbone tensile specimen, 3D-printed dental implant with a 3.4-mm diameter and 3D-printed dental implant with a 4.3-mm diameter are plotted against the number of specimens

osteoblast responses than smooth surfaces with Ra values $<1 \mu \mathrm{m}$ (Shaoki et al. 2016; Ma et al. 2016; González et al. 2021). In the present study, dental implants and dogbone tensile specimens were fabricated using the DMLS technique. The surface topography of the samples was then analysed using confocal microscopy. The results show that the lowest value of the 3D-printed tensile specimen ( $\mathrm{Ra}$ ) was $4.09 \mu \mathrm{m}$ and the highest value was $4.54 \mu \mathrm{m}$. The main findings can be explained as follows: the minimum roughness value $\mathrm{Ra}$ of the $3 \mathrm{D}$-printed dental implant with a diameter of $3.4 \mathrm{~mm}$ was $4.33 \mu \mathrm{m}$ and the maximum $\mathrm{Ra}$ was $9.94 \mu \mathrm{m}$. The surface roughness (Ra) of 3D-printed dental implants with a diameter of $4.3 \mathrm{~mm}$ was reported to be a minimum of $4.58 \mu \mathrm{m}$ and a maximum of $6.02 \mu \mathrm{m}$, which is consistent with previously reported studies (Bernhardt et al. 2021; Ruppert et al. 2017; Kozior and Bochnia 2020).

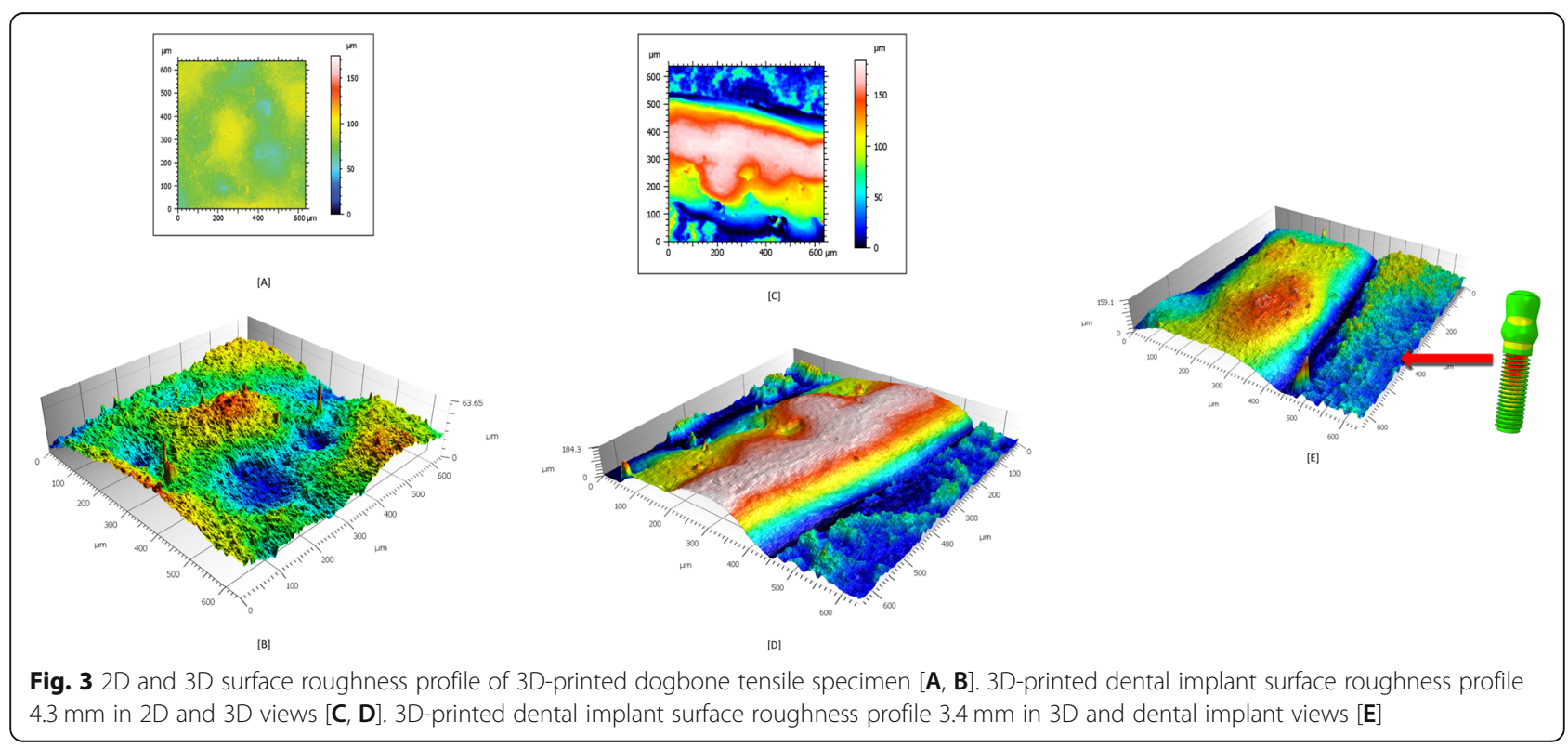




\section{Root mean square ( $\mathrm{Rq}$ and $\mathrm{Sq}$ )}

The root mean square deviation of the surface from the reference plane is evaluated in Fig. 5. Previous studies have shown that the printing orientation has a tremendous effect on the quality of the surface texture and that it is possible to set digital models on the building platform (Kozior and Bochnia 2020). Deviations between models were recorded, and the $\mathrm{Rq}$ value of the 3Dprinted dogbone tensile test specimens was $6.94 \%$, the 3D-printed dental implant with a 3.4-mm diameter was $8.16 \%$ and the 3D-printed dental implant with a $4.3-\mathrm{mm}$ diameter was $7.08 \%$. Percentages are calculated as the average of each point on the graph. Based on the experimental data, it was observed that the $\mathrm{Rq}$ of 3D-printed dental implants with a diameter of $3.4 \mathrm{~mm}$ was higher, which came as no surprise because the geometry of the 3D-printed implant was smaller and complex to build with the additive manufacturing technique. The results of the 3D-printed dogbone tensile test piece in Fig. 5 show that Sq is the lowest percentage of $14.77 \%$ compared to 3D-printed dental implants with a diameter of $3.4 \mathrm{~mm}$ at $52 \%$ and $3 \mathrm{D}$-printed dental implants with a diameter of $4.3 \mathrm{~mm}$ at $53 \%$. This shows that the 3Dprinting process is more effective on improved surfaces when printing flat specimens than complex shapes. The $\mathrm{Rq}$ and Sq results compared favourably to previous studies of the surface treatment performance of TI6AI $4 \mathrm{~V}$ produced by additive manufacturing (Mostafaei et al. 2018; Thakur et al. 2020).

The root mean square ( $R q$ and $\mathrm{Sq})$ parameters are the simplest and most widely used amplitude parameters (Khan and Rahman 2017; Kozior and Bochnia 2020). In addition to the effective value ( $\mathrm{Rq}$ ) parameters investigated in the previous section, both surface roughness and topography are important parameters to consider when selecting implantable materials (Zarei et al. 2020). Furthermore, the evaluation of the $\mathrm{Sq}$ parameter is paramount in the structural applications and initial stability of the dental implants during implantation.

\section{Skewness parameters (Rsk and Ssk)}

The performance of dental implants depends on the surface morphology and the material during their lifespan. Surface functionalisation on these materials depends upon the parameter used to characterise them. The surface roughness characterisation is an important analytical method whereby one can understand the conditions of Ti-64 ELI (Pacella et al. 2019). The skewness was selected as one of the parameters to characterise the surface morphology of the samples. The results for 3.4 mm diameter 3D-printed dental implants Rsk show the lowest percentage of $0.59 \%$ compared to $1.10 \%$ for the 3D-printed dogbone tensile test specimens and 0.93\% for the $4.3 \mathrm{~mm}$ diameter 3D-printed dental implants. The skewness parameter demonstrated a decrease in percentage when used in the samples with complex structures.

One of the greatest difficulties of additive manufacturing is the surface finish, and it might be difficult to use 3D-printed parts in other applications where surface finish is a critical factor (Mostafaei et al. 2018). Metal produced by additive manufacturing has many potential applications in biomedicine, and poor surface treatment of 3D-printed metals significantly deteriorates their resistance to corrosion, wear and fatigue (Ma et al. 2016). Hence, it is vital to characterise 3D-printed samples in order to better understand the application of this material. The findings can be explained as follows: The use of the skewness parameter is recommended for samples with a complex geometry, as it demonstrated minimum values of Rsk of $0.59 \%$ and Ssk of $0.16 \%$ (see Fig. 6).

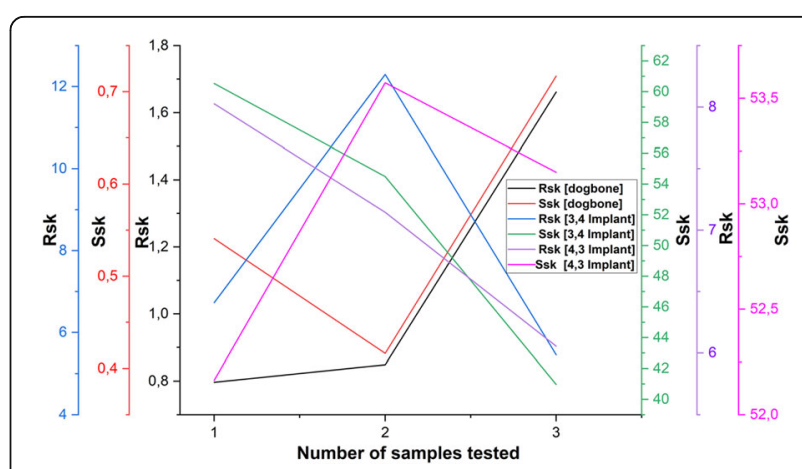

Fig. 6 Graphical representation of 3D-printed specimen results with a comparison of the skewness parameters (Rsk and Ssk) $\mu$ m. 3Dprinted dogbone tensile specimens, 3D-printed dental implant with a 3.4-mm diameter and 3D-printed dental implant with a 4.3-mm diameter are plotted against the number of specimens 
Table 3 Tensile test experimental result

\begin{tabular}{|c|c|c|c|c|}
\hline & $\begin{array}{l}\text { Maximum load } \\
{[\mathrm{N}]}\end{array}$ & $\begin{array}{l}\text { UTS } \\
\text { [MPa] }\end{array}$ & $\begin{array}{l}\text { Yield stress } \\
{[\mathrm{MPa}]}\end{array}$ & $\begin{array}{l}\text { Tensile strain } \\
{[\mathrm{mm}]}\end{array}$ \\
\hline 1 & 7630.58 & 968.35 & 882.23 & 2.36 \\
\hline 2 & 7527.35 & 955.25 & 853.97 & 2.35 \\
\hline 3 & 7689.41 & 961.18 & 854.88 & 2.34 \\
\hline 4 & 7581.17 & 947.65 & 846.60 & 2.26 \\
\hline 5 & 7520.71 & 940.09 & 852.91 & 2.37 \\
\hline Average & 7589.84 & 954.50 & 858.12 & 2.36 \\
\hline
\end{tabular}

\section{Effect of heat treatment on tensile and fatigue properties}

Table 3 shows the results of the tensile testing of 3Dprinted specimens. The results are the average of each of the four specimens tested with standard deviations. Various 3D-printed specimens after fracture are shown in Fig. 7. There was a visible change in the fracture point of the specimen. The maximum load deflection graph is shown in Fig. 8.

The first sample shows the highest yield strength of 882.22 $\mathrm{MPa}$, while the lowest yield strength is sample 4 at $846.60 \mathrm{MPa}$. The graph of the results is given in Table 3 , where the load deflection is plotted. The elongation after breaking the sample was found to be between 2.26 and $2.36 \mathrm{~mm}$. The average maximum load was 7589.84 $\mathrm{N}$, the tensile strength was $954.50 \mathrm{MPa}$ and the elastic limit was $858.12 \mathrm{MPa}$, which agrees with the literature (Moletsane et al. 2016; Gora et al. 2016; Becker et al. 2015b). In the current research, samples made from DMLS titanium (Ti-64 ELI) have shown adequate mechanical properties and are suitable for dental applications.

Table 4 shows 10 experimentally fractured $3.4-\mathrm{mm}$ dental implants and reports the number of cycles and calculation of the service life. The failure of the 3D-

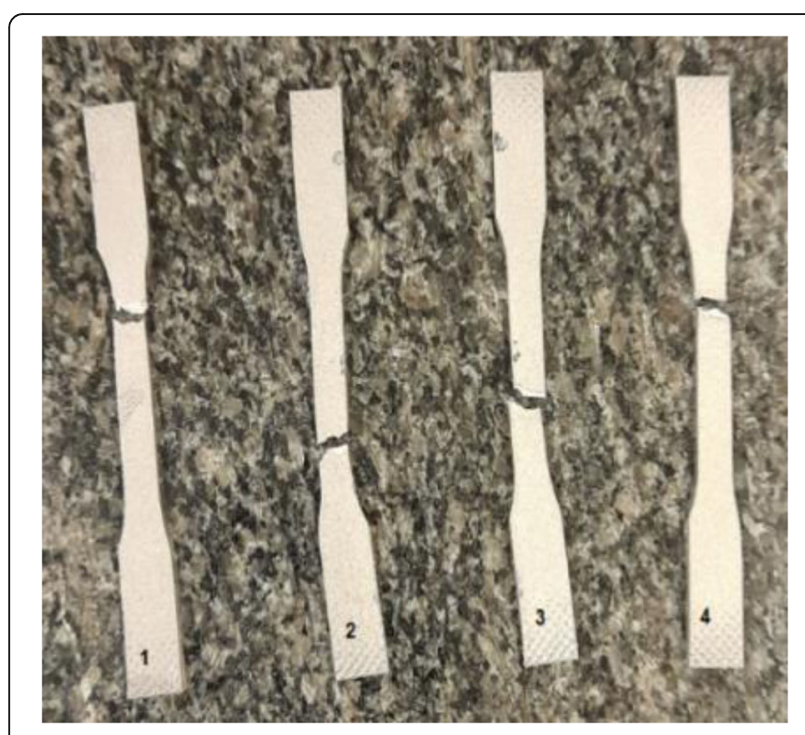

Fig. 7 Fractured tensile test specimen

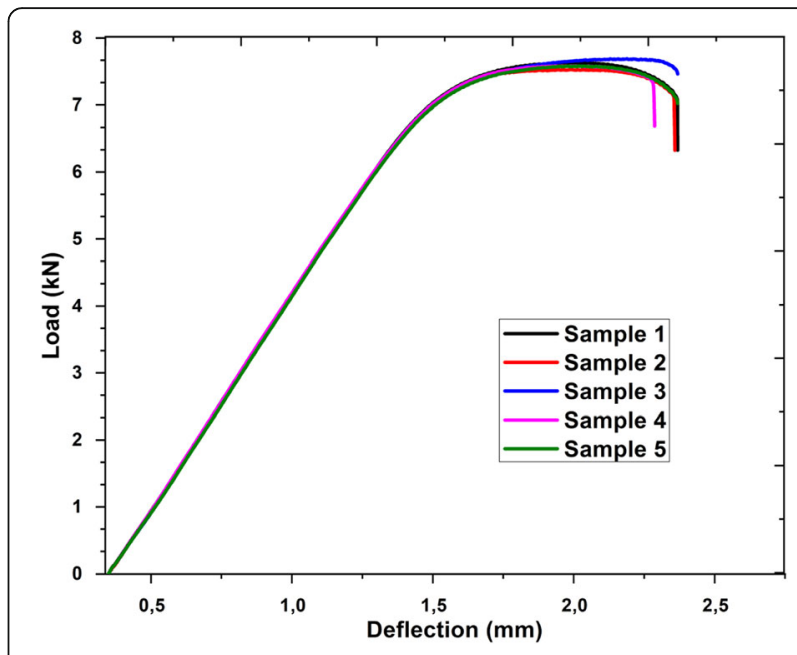

Fig. 8 Ti-64 ELI maximum load deflection curves for 3D printed dogbone. Five repeat results are shown for each

printed dental implant occurred in the second and third threads. The cycle target was set for $5 \times 10^{6}$ cycles according to ISO 14800 and a load of $80 \%$ to the maximum load (BSI Standards Publication dentistry 2016). The average lifetime prediction of 10 3D-printed dental implants was reported to be 20.51 years. The clinical success of 3D-printed dental implants has been seen at a maximum of 29.29 years and a minimum of 15.67 years when a masticatory load of $648.40 \mathrm{~N}$ is applied.

\section{Correlation between mechanical properties and the 3D- printed samples}

This section describes the correlation of surface roughness and mechanical properties under the height parameter, amplitude parameter and skewness parameter. This was done to compare the mechanical properties of the tested samples with the surface roughness values obtained during surface roughness

Table 4 Fatigue experimental results of 3.4-mm diameter dental implant fabricated by DMLS

\begin{tabular}{lll}
\hline Samples & Cycles & Useful life [years] \\
\hline 1 & 262,142 & 29.92 \\
2 & 137,433 & 15.67 \\
3 & 169,624 & 19.36 \\
4 & 169,566 & 19.35 \\
5 & 143,041 & 16.33 \\
6 & 258,874 & 29.55 \\
7 & 140,657 & 16.06 \\
8 & 207,305 & 23.66 \\
9 & 158,304 & 18.07 \\
10 & 150,370 & 17.17 \\
Average & 179,732 & 20.51 \\
\hline
\end{tabular}


Table 5 Maximum load ( $N$ ), ultimate tensile stress (UTS MPa) and tensile strain ( $\mathrm{mm}$ ) average over five repeat tests for the Ti-64 ELI samples graphed in Fig. 8 with measured mean roughness Ra, Sa, Rq, Sq, Rsk and Ssk

\begin{tabular}{lllllllllll}
\hline Tensile test & Surface roughness conditions & Ra & Rq & Rsk & Sq & Sa & Ssk & Maximum load $(\boldsymbol{N})$ & UTS (MPa) & Tensile strain $(\mathbf{m m})$ \\
\hline 1 & $10 \times$ horizontal direction & 4.09 & 5.87 & 0.79 & 13.71 & 10.62 & 0.361 & 7630.58 & 968.35 & 2.02 \\
2 & $10 \times$ horizontal direction & 4.48 & 5.97 & 0.85 & 12.11 & 9.36 & 0.31 & 7527.35 & 955.25 & 2.18 \\
3 & $10 \times$ horizontal direction & 4.54 & 5.98 & 1.11 & 12.69 & 9.92 & 0.48 & 7689.41 & 961.18 & 2.43
\end{tabular}

Table 6 Load $(N)$, cycles and useful life (years) average over 10 repeat tests for the Ti-64 ELI samples graphed in Table 4 with measured mean roughness Ra, Sa, Rq, Sq, Rsk and Ssk

\begin{tabular}{lllllllllll}
\hline Fatigue test (3.4) & Surface roughness conditions & Ra & Rq & Rsk & Sq & Sa & Ssk & Load $(\boldsymbol{N})$ & Cycles & Useful life (years) \\
\hline 1 & $10 \times$ horizontal direction & 5.34 & 6.73 & 0.61 & 60.53 & 53.41 & 0.25 & 648.4 & 26214 & 29.92 \\
2 & $10 \times$ horizontal direction & 9.94 & 12.29 & 0.57 & 54.49 & 46.71 & 0.18 & 648.4 & 13743 & 15.67 \\
3 & $10 \times$ horizontal direction & 4.33 & 5.46 & 0.61 & 40.98 & 35.84 & 0.08 & 648.4 & 16962 & 19.36 \\
\hline
\end{tabular}

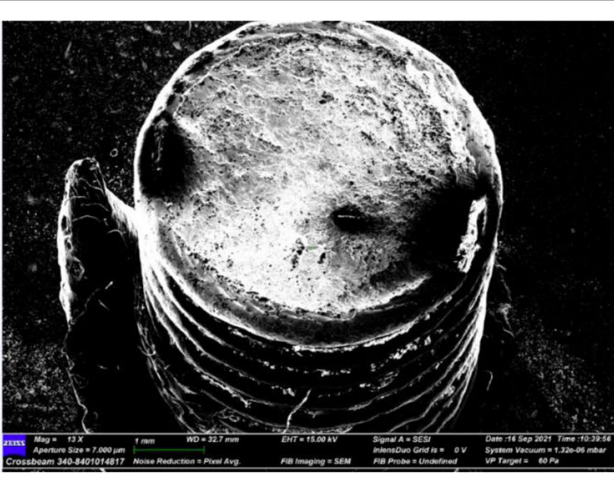

[A]

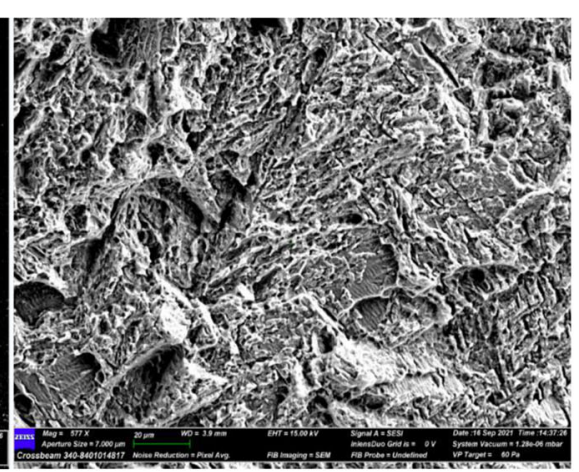

[B]

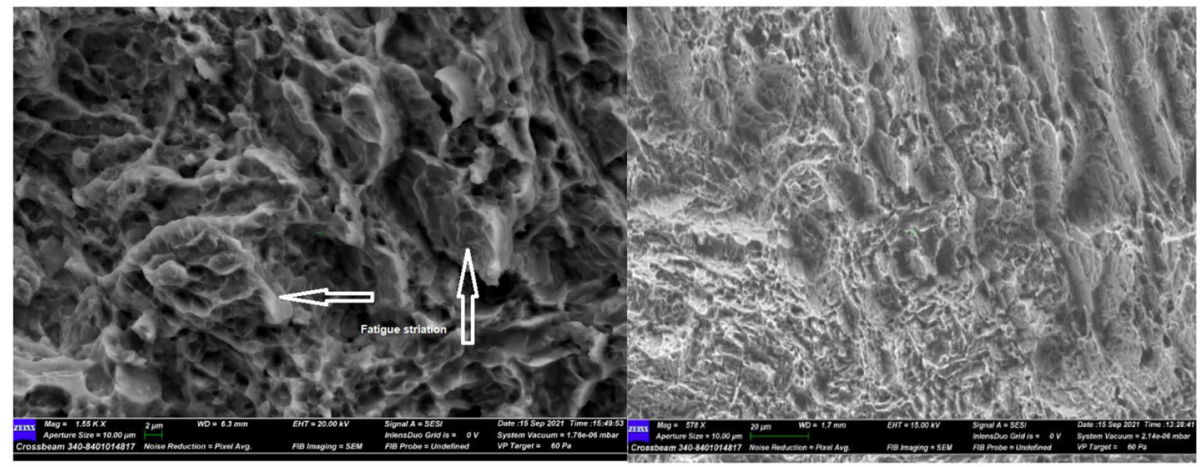

[C]

[D]

Fig. 9 SEM images of fractured surface. A Gross view of the fracture surface. B Fatigue crack propagation. C Fatigue striations. D Ductile dimples 
measurements. The parameters were calculated at average of each specimen. The acquired fatigue life and mechanical properties were linked to surface roughness in order to better understand the morphology or usefulness of 3D-printed Ti-64 ELI samples printed with a direct laser sintered machine. The outcome of the results is addressed in the following test.

The results from Table 5 show that Ra increases by $1.4 \%$ when ultimate tensile stress (UTS) decreases from 968.35 to $955.25 \mathrm{MPa}$ and by $0.6 \%$ when the UTS increases to $961.18 \mathrm{MPa}$. It was also noticed from the same table that Rsk and Rq increase with the decrease in UTS. These surface roughness parameters have a significant impact on the mechanical properties of 3D-printed samples under study.

It was noticed from Table 6 that when the cycles decrease by 137,433 from 262,142, the arithmetical mean height ( $\mathrm{Ra}$ ) for the 3D-printed dental implant also increases. In Table 6, when the cycles decrease from 262,142 to 137,433 , Ra increases by $90.74 \%$, revealing lower cycle gain. It shows a $23 \%$ increase in Ra when the cycle increases from 137,433 to 169,624 . In the same figure, it can be seen that Rsk and $\mathrm{Rq}$ also increase as the cycles decrease. From Table 6, it was noticed that cycles changes due to surface roughness parameters, and it can be seen that surface roughness has an impact on the mechanical and fatigue properties.

\section{Fractographic analysis results}

The fractured dental implants were collected and analysed under a microscope to determine the fracture mode of 3D-printed dental implants.

The samples failed at the level of the simulated bone in the implant body, see Fig. 9. Dimple size was observed to be small, which is shown by SEM and fracture morphology. At higher magnification, typical fatigue striations were found in this smooth area next to the origin of the failure, indicating the stages of propagation of the fatigue crack, see Fig. 9C. At the lowest magnification, this area looked quite smooth, see Fig. 9A. In addition, it was observed that the distribution of the material was $\mathrm{Ti}$ 90.9\%, $\mathrm{Al} 4.7 \%$ and $\mathrm{V} 4.4 \%$, and EDS images are shown in Fig. 10A-C.

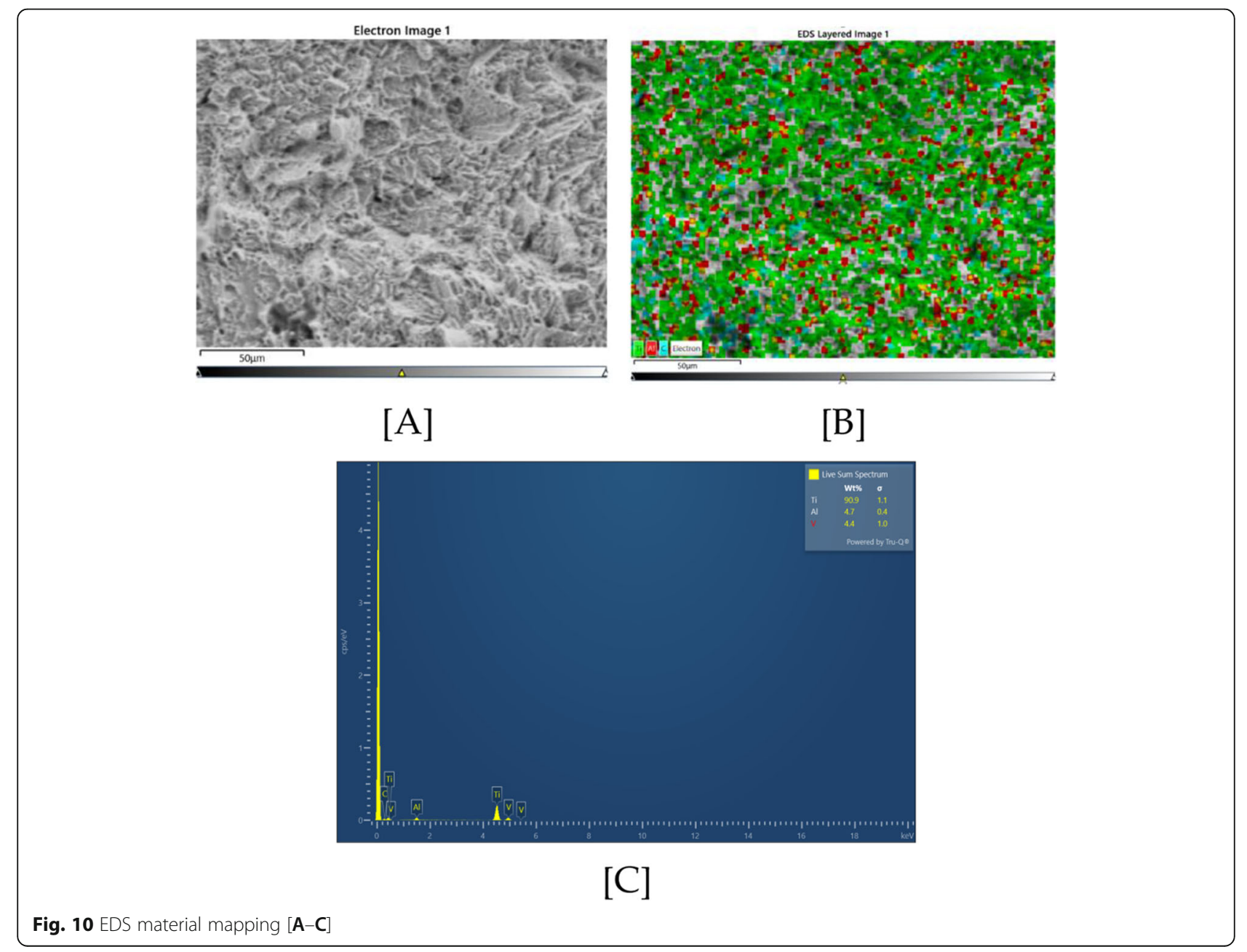




\section{Conclusions}

In the current study, the effects of surface roughness and mechanical properties of 3D-printed dental implants with diameters of $3.4 \mathrm{~mm}$ and $4.3 \mathrm{~mm}$ and 3D-printed dogbone tensile specimens were addressed. The outcomes of the study are as follows:

- It was observed that the crest and flank exhibited a smooth surface while the root had a rough surface for the 3D-printed dental implants, as shown in Fig. 3. This could mean that between the threads, it was difficult for the 3D printer to print a smooth surface due to the size and shape of the threads.

- It has been observed that samples with complex shapes show a higher roughness surface and pose the greatest difficulty in additive manufacturing when assessing the surface finish. In terms of surface roughness $(\mathrm{Ra})$, the best results were obtained with a 3D-printed dogbone with an average of $4.37 \mu \mathrm{m}$, $4.3 \mathrm{~mm}$ 3D-printed dental with an average of $5.38 \mu \mathrm{m}$ and $3.4 \mathrm{~mm} 3 \mathrm{D}$-printed dental implant with an average $6.54 \mu \mathrm{m}$.

- Ra increases by $1.4 \%$ when the ultimate tensile stress (UTS) decreases to $955.25 \mathrm{MPa}$ at $968.35 \mathrm{MPa}$ and increases by $0.6 \%$ when the UTS increases to 961.18 $\mathrm{MPa}$. It can also be seen from Fig. 8 that Rsk and Rq increase as UTS decreases.

- As a result of fatigue, when the cycles decrease from 262,142 to 137,433 , Ra increased by $90.74 \%$; this huge difference adversely affects the fatigue properties of 3D-printed dental implants.

- For 3D-printed dental implants, the greater the surface roughness, the lower the mechanical properties, which in turn shortens the life of the implant and reduces its performance.

- From Table 6, it was noticed that cycles change due to surface roughness parameters.

\section{Limitation}

Fatigue tests were limited to a 3.4- $\mathrm{mm}$ diameter 3Dprinted dental implant with 10 samples; the tensile test was performed on 5 samples due to the cost of $3 \mathrm{D}$ printing, and the heat treatment was done for $2 \mathrm{~h}$ held at $800{ }^{\circ} \mathrm{C}$.

\section{Abbreviations}

DMLS: Direct metal laser sintered; EBM: Electron beam melting; ELI: Extra-low interstitial; Ra: Arithmetical mean height ( $\mu \mathrm{m})$; Ra: Arithmetical mean height $(\mu \mathrm{m}) ;$ Rsk: Skewness $(\mu \mathrm{m}) ;$ Rq: Root mean square $(\mu \mathrm{m})$; Sa: Amplitude parameters (average of ordinates) $(\mu \mathrm{m})$; Ssk: Surface skewness $(\mu \mathrm{m})$; Sq: Root mean square roughness $(\mu \mathrm{m})$; stl: Standard translation language
\end{abstract}

\section{Acknowledgements}

The research was supported by the Tshwane University of Technology and the University of South Africa (Unisa). The experiments were performed in biomechanics laboratory facilities at Unisa's Science Campus in Johannesburg, South Africa.

\section{Authors' contributions}

LC developed the project, conceptualised the work, conducted experiments and analysis and wrote the paper. The authors read and approved the final manuscript.

\section{Funding}

The project was funded through a Tshwane University of Technology scholarship and Unisa research funding.

\section{Availability of data and materials}

The datasets used and/or analysed during the study are available from the corresponding author on reasonable request.

\section{Declarations}

Competing interests

The authors declare that they have no competing interests.

Received: 28 May 2021 Accepted: 26 October 2021

Published online: 17 November 2021

\section{References}

Ahsan, M. M. (2016). 3D printing and titanium alloys: a paper review. Eur Acad Res, III(10), 11144-11154.

Barman, A., \& Das, M. (2018). Nano-finishing of bio-titanium alloy to generate different surface morphologies by changing magnetorheological polishing fluid compositions. Precis Eng, 51, 145-152. https://doi.org/10.1016/j. precisioneng.2017.08.003.

Becker, T., van Rooyen, M., \& Dimitrov, D. (2015a). Heat treatment of TI-64L-4V produced by lasercuring. South Afr J Ind Eng, 26(2), 93-103.

Becker, T. H., Beck, M., \& Scheffer, C. (2015b). Microstructure and mechanical properties of direct metal laser sintered Ti-6Al-4V. South Afr J Ind Eng, 26(1), 1-10. https://doi.org/10.7166/26-1-1022.

Bernhardt, A., Schneider, J., Schroeder, A., Papadopoulous, K., Lopez, E., Brückner, F., \& Botzenhart, U. (2021). Surface conditioning of additively manufactured titanium implants and its influence on materials properties and in vitro biocompatibility. Mater Sci Eng C, 119, 111631. https://doi.org/10.1016/j. msec.2020.111631.

Bhardwaj, T., \& Shukla, M. (2018). Effect of laser scanning strategies on texture, physical and mechanical properties of laser sintered maraging steel. Mater Sci Eng A, 734, 102-109. https://doi.org/10.1016/j.msea.2018.07.089.

BSI Standards Publication dentistry, "BSI standards publication dentistry —implants—dynamic loading test for endosseous dental implants," 2016.

Chang Tu, C., Tsai, P. I., Chen, S. Y., Kuo, M. Y. P., Sun, J. S., \& Chang, J. Z. C. (2020). 3D laser-printed porous Ti6Al4V dental implants for compromised bone support. J Formos Med Assoc, 119(1P3), 420-429.

Galati, M., Minetola, P., \& Rizza, G. (2019). Surface roughness characterisation and analysis of the electron beam melting (EBM) process. Materials, 12(13).

Godbey, B. (2007). Surface finish control of 3D printed metal tooling. Clemson University.

González, J. E., Armas, G. ., Negrin, J., Beltrán, A. M., Trueba, P., Gotor, F. J., .. Torres, Y. (2021). Influence of successive chemical and thermochemical treatments on surface features of Ti6Al4V samples manufactured by SLM. Metals, 11(2), 1-13. https://doi.org/10.3390/met11020313.

Gora, W. S., Tian, Y., Cabo, A. P., Ardron, M., Maier, R. R. J., Prangnell, P., ... Hand, D. P. (2016). Enhancing surface finish of additively manufactured titanium and cobalt chrome elements using laser based finishing. Phys Procedia, 83, 258-263. https://doi.org/10.1016/j.phpro.2016.08.021.

Jemat, A., Ghazali, M. J., Razali, M., \& Otsuka, Y. (2015). Surface modifications and their effects on titanium dental implants. Biomed Res Int, 2015.

Khan, M. D. A. R., \& Rahman, M. M. (2017). Surface finish characteristics of titanium alloy in a non conventional technique. Int Conf Recent Trends Eng Mater Sci, 4(9), 9352-9355.

Kozior, T., \& Bochnia, J. (2020). The influence of printing orientation on surface texture parameters in powder bed fusion technology with $316 \mathrm{~L}$ steel. Micromachines, 11(7)

Kunrath, M. F. (2020). Customized dental implants: manufacturing processes, topography, osseointegration and future perspectives of 3D fabricated implants. Bioprinting, 20, e00107. https://doi.org/10.1016/j.bprint.2020.e00107. 
Kuss, D. J., Griffiths, M. D., Binder, J. F., \& Street, B. (2015). Heat treatment of TI6AL-4V produced by lasercusing. Int RAPDASA Conf, 26(2) August $2015 \mathrm{~V}$, 93-103.

Le Guéhennec, L., Soueidan, A., Layrolle, P., \& Amouriq, Y. (2007). Surface treatments of titanium dental implants for rapid osseointegration. Dent Mater, 23(7), 844-854. https://doi.org/10.1016/j.dental.2006.06.025.

Ma, C., Dong, Y., \& Ye, C. (2016). Improving surface finish of 3D-printed metals by ultrasonic nanocrystal surface modification. Procedia CIRP, 45, 319-322. https://doi.org/10.1016/j.procir.2016.02.339.

Marenzi, G., Impero, F., Scherillo, F., Sammartino, J. C., Squillace, A., \& Spagnuolo, G. (2019). Effect of different surface treatments on titanium dental implant micro-morphology. Materials, 12(5).

Materials, P., Materials, E. I., Matrix, P., Materials, C., \& Specimens, P. (2006). Standard test method for tensile properties of plastics 1, (pp. 1-15).

Moletsane, M. G., Krakhmalev, P., Kazantseva, N., du Plessis, A., Yadroitsava, I., \& Yadroitsev, I. (2016). Tensile properties and microstructure of direct metal laser-sintered Ti6Al4V (ELI) alloy. South Afr J Ind Eng, 27(3), 110-121.

Mooney, B., \& Kourousis, K. I. (2020). A Review of of Maraging Factors Affecting Properties of Powder Bed Fusion. Metals, 10(9), 1273.

Mostafaei, A., Neelapu, S. H. V. R., Kisailus, C., Nath, L. M., Jacobs, T. D. B., \& Chmielus, M. (2018). Characterizing surface finish and fatigue behavior in binder-jet 3D-printed nickel-based superalloy 625. Addit Manuf, 24, 200-209. https://doi.org/10.1016/j.addma.2018.09.012.

Nagy, W. W., \& Griggs, J. A. (2018). Fatigue lifetime prediction of a reduceddiameter dental implant system: numerical and experimental study. Dent Mater, 1-11.

Obiukwu, O., Martin, N., Okafor, B., Lawa, G., Obiukwu, L. G. O., Nwafor, M., $\&$ Okafor, B. (2015). The effect of surface finish on the low cycle fatigue of low and medium carbon steel. Int Conf Mech Ind Engg Available: https://www.researchgate.net/publication/335240807_The Effect_of_Surface_Finish_on_the_Low_Cycle_Fatigue_of_Low_and_ Medium_Carbon_Steel.

Oliveira, T. T., \& Reis, A. C. (2019). Fabrication of dental implants by the additive manufacturing method: a systematic review. J Prosthet Dent, 122(3), 1-5. https://doi.org/10.1016/j.prosdent.2019.01.018.

Öztürk, B., \& Kara, F. (2020). Calculation and estimation of surface roughness and energy consumption in milling of 6061 alloy. Adv Mater Sci Eng, 2020.

Pacella, M., Nekouie, V., \& Badiee, A. (2019). Surface engineering of ultra-hard polycrystalline structures using a nanosecond $\mathrm{Yb}$ fibre laser: effect of process parameters on microstructure, hardness and surface finish. J Mater Process Technol, 266(June 2018), 311-328.

Ren, B., et al. (2021). Improved osseointegration of 3D printed Ti-6Al-4V implant with a hierarchical micro/nano surface topography: an in vitro and in vivo study. Mater Sci Eng C, 118, 111505.

Ruppert, D. S., Harrysson, O. L. A., Marcellin-Little, D. J., Abumoussa, S., Dahners, L. E., \& Weinhold, P. S. (2017). Osseointegration of coarse and fine textured implants manufactured by electron beam melting and direct metal laser sintering. 3D Print Addit Manuf, 4(2), 91-97. https://doi.org/10.1089/3dp.2017.0008.

Shaoki, A., Xu, J. Y., Sun, H., Chen, X. S., Ouyang, J., Zhuang, X. M., \& Deng, F. L. (2016). Osseointegration of three-dimensional designed titanium implants manufactured by selective laser melting. Biofabrication, 8(4), 1-10. https://doi. org/10.1088/1758-5090/8/4/045014.

Sneddon, S., Xu, Y., Dixon, M., Rugg, D., Li, P., \& Mulvihill, D. M. (2020). Sensitivity of material failure to surface roughness: a study on titanium alloys Ti64 and Ti407. Mater Des, 200, 109438.

Suh, A. Y., Polycarpou, A. A., \& Conry, T. F. (2003). Detailed surface roughness characterization of engineering surfaces undergoing tribological testing leading to scuffing. Wear, 255(1-6), 556-568. https://doi.org/10.1016/50043-1 648(03)00224-2.

Tang, Z., Huang, F., \& Peng, H. (2021). Effect of 3D roughness characteristics on bonding behaviors between concrete substrate and asphalt overlay. Constr Build Mater, 270, 121386. https://doi.org/10.1016/j.conbuildmat.202 0.121386 .

Thakur, A., Rao, P. S., \& Khan, M. Y. (2020). Study and optimization of surface roughness parameter during electrical discharge machining of titanium alloy (Ti-6246). Mater Today Proc

Vaidya, A., \& Pathak, K. (2019). Mechanical stability of dental materials. In Applications of Nanocomposite Materials in Dentistry, (pp. 285-305). Woodhead Publishing.

Xiao, W. L., Chen, H. B., \& Yin, Y. (2012). Effects of surface roughness on the fatigue life of alloy steel. Key Eng Mater, 525-526(October 2015), 417-420.
Zarei, H., Rosaria Marulli, M., Paggi, M., Pietrogrande, R., Üffing, C., \& Weißgraeber, $P$. (2020). Adherend surface roughness effect on the mechanical response of silicone-based adhesive joints. Eng Fract Mech, 240.

\section{Publisher's Note}

Springer Nature remains neutral with regard to jurisdictional claims in published maps and institutional affiliations.

\section{Submit your manuscript to a SpringerOpen ${ }^{\circ}$ journal and benefit from:}

- Convenient online submission

- Rigorous peer review

- Open access: articles freely available online

High visibility within the field

- Retaining the copyright to your article

Submit your next manuscript at $\boldsymbol{\nabla}$ springeropen.com 